\title{
Rancang Bangun Aplikasi Pembelajaran Makhraj Huruf Al-Qur'an Untuk Anak-anak
}

\author{
Gitadea Laksono,Steven Sentinuwo, M. Dwisnanto Putro \\ Teknik InformatikaUniversitas Sam Ratulangi Manado, Indonesia \\ 120216146@student.unsrat.ac.id, steven@unsrat.ac.id,dwisnantoputro@unsrat.ac.id
}

\begin{abstract}
Abstrak-"Dan Bacalah Al-Qur'an itu dengan perlahan-lahan". (Al-Muzzammil: 4). Dalam ayat tersebut dikatakan bahwa dalam membaca Al-Qur'an itu harus mengikuti aturan yang diberikan (perlahanlahan). . Aturan dalam membaca Al-Qur'an adalah tajwid. Dalam tajwid terdapat makhraj huruf, dimana makhraj huruf merupakan tempat keluarnya huruf hijaiyah saat dilafazkan. Dalam proses pembelajran sering terjadi seorang pengajar mengalami kesulitan untuk menyampaikan suatu materi kepada peserta didik. Tujuan penelitian ini adalah membangun atau membuat suatu aplikasi pembelajaran makhraj huruf Al-Qur'an yang dapat membantu dalam proses pembelajaran makhraj huruf. Metode yang digunakan dalam pembengunan aplikasi ini adalah RAD (Rapid Aplicaton Development).RAD yaitu suatu pendekatan berorientasi objek terhadap pengembangan sistem yang mencakup suatu metode pengembangan serta perangkat-perangkat lunak. Hasil dari penelitian ini adalah aplikasi pembelajaran tentang makhraj huruf Al-Qur'an untuk anak-anak berbasis android. Aplikasi yang dihasilkan mempunyai materi makhraj huruf yang berisikan 29 huruf hijaiyah, aplikasi ini memiliki dua karakter didalamnya yaitu laki-laki dan perempuan. Aplikasi pembelajaran makhraj huruf ini juga memiliki firtur kuis, dimana kuis ini berisikan lima belas pertanyaan dan pertanyaan akan di acak.

Kata kunci : Huruf Hijaiyah, Rapid Aplication Development, Makhraj Huruf
\end{abstract}

\section{PENDAHULUAN}

Al-Qur'an adalah kitab suci umat Islam.AlQur'an adalah firman ALLAH SWT.Yang disampaikan kepada Nabi Muhammad SAW.melalui perantara malaikat jibril. Dalam membaca AL-Qur'an, ada tata caranya sendiri.Al-Qur'an mempunyai etika pembacaannya sendiri, sesuai dengan firman ALLAH SWT."Dan Bacalah Al-Qur'an itu dengan perlahan-lahan". (Al-Muzzammil: 4). Dimaksudkan dalam surat itu, apabila kia membaca AlQur'an harus perlahan-lahan, memperhatikan makhrajnya dan diambil hikmahnya. Dimana makhraj huruf ini adalah tempat keluar huruf hijaiyah saat dilafazkan.Huruf hijaiyah merupakan huruf penyusun kata dalam AlQur'an. Seperti halnya di Indonesia yang memiliki huruf alphabet dalam menyusun sebuah kata menjadi kalimat, huruf hijaiyah juga memiliki peran yang sama. Jumlah huruf hijaiyah ada 30 huruf.

Perkembangan teknologi semakin pesat dan cepat, khususnya teknologi informasi dan komunikasi.Dengan berkembangnya suatu jaman, media dan teknologi memiliki pengaruh penting terhadap pendidikan.Banyak media pembelajaran yang dapat digunakan, salah satu media yang digunakan yaitu Aplikasi Pembelajaran pada gadget. Dalam aplikasi pembelajaran mampu melatih pengetahuan, keterampilan dan ketepatan dalam sistem pembelajaran dengan cara yang lebih menarik

Kegiatan mengajar merupakan pekerjaan yang tidak mudah bagi sebagian orang. Terutama jika yang diberi pengajaran adalah anak-anak. Dalam proses pembelajaran sering terjadi seorang pengajar mengalami kesulitan untuk menyampaikan suatu materi pelajaran kepada peserta didik, sehingga terkesan pelajaran tersebut membosankan. Permasalahan seperti ini biasanya terjadi pada peserta didik terhadap pelajaran yang membutuhkan pemahaman yang lebih tinggi, di antaranya adalah pembelajaran membaca Al-Qur'an beserta makhrajnya.Dari permasalahan tersebut maka dibutuhkan suatu aplikasi yang dapat merangsang anak-anak untuk belajar mengaji.Dimana aplikasi ini dapat menarik anakanak untuk belajar makhraj huruflebih dini.

\section{LANDASAN TEORI}

\section{A. M-Learning}

Mobile-Learning adalah suatu pendekatan pembelajaran yang melibatkan device bergerak seperti telepon genggam, PDA, Laptop dan tablet PC, dimana pengguna dapat mengakses materi, arahan dan aplikasi yang berkaitan dengan 10 pelajaran tanpa dibatasi oleh ruang dan waktu, dimanapun dan kapanpun mereka berada. Mobile learning didefinisikan oleh Clark Quinn (Quinn 2000) sebagai : The intersection of mobile computing and e-learning: accessible resources wherever you are, strong search capabilities, rich interaction, powerful support for effective learning, and performancebased assessment E-learning independent of location in time or space.Berdasarkan definisi tersebut, mobile learning merupakan model pembelajaran yang memanfaatkan teknologi informasi dan komunikasi. Mobile learning mengacu kepada penggunaan perangkat teknologi informasi (TI) genggam dan bergerak, seperti PDA, telepon genggam, laptop dan tablet PC, dalam pengajaran dan pembelajaran. M-learning adalah pembelajaran yang unik karena pembelajar dapat mengakses materi pembelajaran, arahan dan aplikasi yang berkaitan dengan pembelajaran, kapanpun dan dimanapun M-learning memungkinkan adanya lebih banyak kesempatan untuk kolaborasi secara langsung dan berinteraksi secara informal diantara pembelajar. [1].

\section{B. Huruf Hijaiyah}

Dalam bahasa arab, terdapat huruf hijaiyah. Huruf Hijaiyah merupakan huruf penyusun kata dalam Al Qur 'an. Seperti halnya di Indonesia yang memilki huruf alfabet dalam menyusun sebuah kata menjadi kalimat, huruf hijaiyah juga memiliki peran yang sama. Huruf hijaiyah berjmlah 30 huruf. Huruf tersebut bisa dilihat pada gambar 1 . 


\begin{tabular}{|c|c|c|c|c|c|}
\hline $\mathrm{C}_{\mathrm{Ha}}$ & $\underset{\text { Jim }}{ج}$ & 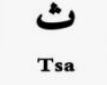 & $\underset{T a}{ت}$ & $\underset{\mathrm{Ba}}{4}$ & $\begin{array}{c}1 \\
\text { Alif }\end{array}$ \\
\hline س & $\underset{z a}{j}$ & $\underset{\text { Ro }}{J}$ & $\begin{array}{c}\mathbf{J} \\
\text { Dzal }\end{array}$ & $\begin{array}{l}\Delta \\
\text { Dal }\end{array}$ & Kho \\
\hline$\varepsilon$ & $\begin{array}{c}\text { b } \\
\text { Dzo }\end{array}$ & $\begin{array}{c}b \\
\text { Tho }\end{array}$ & ض Dlod & $\underbrace{ص}_{\text {Shod }}$ & Syin \\
\hline$\underset{\text { Mim }}{\stackrel{P}{2}}$ & $\underset{\text { Lam }}{J}$ & $\begin{array}{l}\text { 5) } \\
\text { Kaf }\end{array}$ & $\begin{array}{c}\text { قof } \\
\text { Qo }\end{array}$ & Ga & Ghin \\
\hline $\begin{array}{l}\text { Yak } \\
\text { Yak }\end{array}$ & $\underset{\text { Hamzah }}{\&}$ & $\begin{array}{c}У \\
\text { Lam Alif }\end{array}$ & $\begin{array}{c}\infty \\
\text { Hha }\end{array}$ & $\begin{array}{c}9 \\
\text { wawu }\end{array}$ & $\underset{\text { Nun }}{\dot{v}}$ \\
\hline
\end{tabular}

Gambar 1. Huruf Hijaiyah

Sumber: Ilmu Tajwid, Huruf Hijaiyah

\section{Makhraj Huruf}

Makhraj artinya tempat keluar. Makharijul Huruf adalah tempat keluarnya huruf-huruf hijaiyah pada saat dilafalkan. Pembaca Al-Quran yang baik, bukan saja harus mengetahui hukum-hukum tajwid, tetapi juga harus memperhatikan dan memahami makhraj dan sifat dari huruf-huruf yang dibacakan.Tempat keluar huruf hijaiyah dapat dilihat pada gambar 2. Tempat keluar huruf $\mathrm{Al}$ Qur'an ada tujuh belas (17) tempat yang diklasifikasikan menjadi 5 tempat, yaitu:

1. Al-Jaufi / Rongga Mulut ( الجوف ) yaitu: Makhraj Lubang mulut dan tenggorokan tengah: merupakan tempat keluar huruf mad. Huruf mad adalah : 1 g

2. Al-Halqi / Tenggorokan ( الحلق ) yaitu:

a. Makhraj Tenggorokan bawah: yang mendekati dada merupakan tempat keluar huruf : i, •.

b. Makhraj Tenggorokan tengah: adalah tempat keluar huruf: $\tau, \varepsilon$

c. Makhraj Tenggorokan atas: adalah tempat keluar huruf : $\dot{\boldsymbol{c}}, \dot{\varepsilon}$

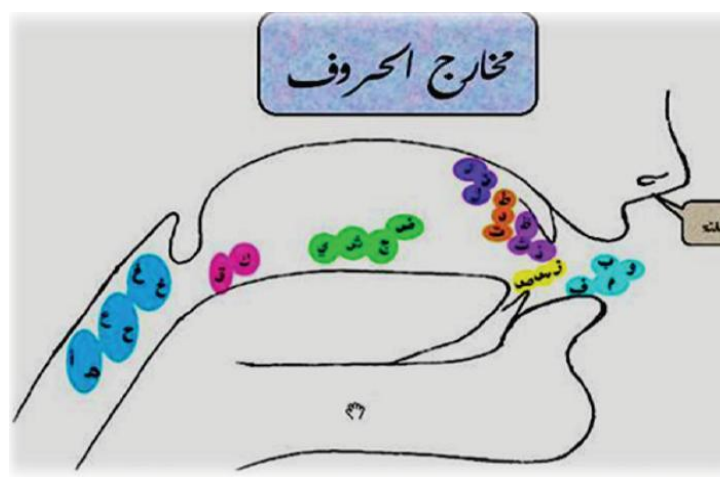

Gambar 2. Tempat Keluar Huruf Hijaiyah Sumber: Tajwid Qarabasy, United Islamic Cultural Centre of Indonesia, $\mathrm{p} 9$
3. Al-Lisani / Lidah ( اللسان ) yaitu:

a. Makhraj pangkal lidah dengan langit-langit yang lurus di atasnya adalah tempat keluar huruf : ق

b. Makhraj pangkal lidah dengan langit-langit yang lurus di atasnya agak keluar sedikit dari makhraj Qaf adalah tempat keluar huruf :

c. Makhraj lidah bagian atas dengan langitlangit di atasnya ada-lah tempat keluar huruf :

d. Makhraj salah satu tepi lidah dengan geraham atas adalah tempat keluar huruf: ض

e. Makhraj lidah bagian depan setelah makhraj dhad dengan gusi atas adalah tempat keluar huruf : J

f. Makhraj ujung lidah dengan gusi atas keluar sedikit dari makhraj lam: adalah tempat keluar huruf : ن

g. Makhraj ujung lidah lebih agak ke dalam sedikit dari makhraj nun adalah tempat keluar huruf : J

h. Makhraj ujung lidah dengan pangkal dua buah gigi atas adalah tempat keluar huruf : ث, b, د

i. Makhraj ujung lidah dengan rongga antara gigi atas dengan gigi bawah yang lebih dekat dengan gigi bawah adalah tempat keluar huruf: $\boldsymbol{\omega}$

j. Makhraj ujung lidah dengan ujung dua buah gigi atas adalah tempat keluar huruf : ظ,

4. Asy-Syafawi /bibir ( الثفوي ) yaitu:

a. Makhraj bagian tengah dari bibir bawah dengan ujung dua buah gigi atas: adalah tempat keluar huruf : ف

b. Makhraj bibir, kedua bibir atas dan bawah bersama-sama adalah tempat keluar huruf : و, ب

5. Al-Khaisyhumi / Pangkal Hidung ( الخيشوم ) yaitu: Makhraj Al-Khaisyum, pangkal hidung merupakan tempat keluar (Dengung).

a. Pangkal Hidung bagian dalam, yaitu hurufhuruf yang dibaca dengung (ghunnah):

1) Pada hukum Nun Sukun $(\dot{j})$ dan tanwin $(\stackrel{\equiv}{-},-\stackrel{-}{-})$, yaitu Ikhfa Haqiqi, Iqlab, dan Idgham Bighunnah.

2) Pada hukum Mim Sukun ( $\underset{p}{p}$ ), yaitu Ikhfa Syafawi dan Idgham Mitslain,

3) Hukum Ghunnah Musyaddadah, yaitu huruf Mim Bertasydid ( $ّ)$ dan Nun Bertasydid (ن்).

4) Hukum Idgham Mutajanisain hanya untuk Ba Sukun ( bertemu dengan huruf Mim Berharakat ( $p$ ).

5) Hukum Mad Lazim Harfi Mukhaffaf hanya dikhususkan untuk huruf 'Ain tanpa harakat ( $)$ [2]. 
D. Unity

Unity merupakan game engine, yaitu software yang digunakan untuk memudahkan dalam membuat game.Salah satu game engine yang populer di kalangan indiegame developer adalah Unity3d. Unity $3 d$ pada awalnya adalah sebuah game engine $3 \mathrm{D}$, namun mulai dari versi 4.3 unity mensupport secara native pengembangan game 2D dengan menambahkan feture-feture khusus untuk game 2D, seperti editor dapat di setup ke mode 2D, physics $2 d$, sprire render dll. Unity sendiri adalah sebuah game engine yang multi platform, jadi game yang di kembangkan dengan unity $3 d$ dapat di jalankan di berbagai platform yang berbeda dari desktop, web, mobile dan console[3].

\section{E. Blender}

Blender juga tersedia untuk sistem operasi 32 bit dan 64 bit baik untuk Windows, Linux, Free BSD, dan Mac OSX. Akan tetapi, saat ini blender sudah tidak mendukung untuk sistem operasi Windows XP. Blender sendiri merupakan software 3 dimensi yang ringan dengan ukuran file yang kurang dari 100MB. Oleh karena itu, untuk menggunakan Blender, tidak harus menggunakan spesifikasi komputer yang terlalu tinggi. Bahkan blender bisa dijalankan dengan baik pada komputer dengan prosesor dual core[4].

\section{F. Adobe Photoshop}

Adobe Photoshop Merupakan Software / Perangkat Lunak Editor yang dibuat oleh Adobe System, yang dikhususkan untuk pengeditan gambar, foto, dan pembuatan efek. Software ini dianggap sebagai produk yang terbaik yang di buat oleh Adobe System.

\section{G. Visual Studio}

Microsoft Visual Studio merupakan sebuah perangkat lunak lengkap yang dapat digunakan untuk melakukan pengembangan aplikasi, baik itu aplikasi bisnis, aplikasi personal, ataupun komponen aplikasinya, dalam bentuk aplikasi console, aplikasi Windows, ataupun aplikasi Web. Visual Studio mencakup kompiler, SDK, Integrated Development Environment (IDE), dan dokumentasi (umumnya berupa MSDN Library)[5].

\section{METODOLOGI PENELITIAN}

\section{A. Metode Pengumpulan Kebutuhan Informasi}

Pada tahap ini, penulis mengumpulkan data melalui media buku, paper riset, jurnal, skripsi, tugas akhir, referensi-referensi melalui internet yang berkaitan dengan judul penelitian. Data yang dikumpulkan penulis adalah data mengenai metode RAD (Rapid Aplication Development) mengenai tahap-tahapanya, kegunaannya dan diagram apa saja yang akan dibuat bila menggunakan metode RAD.

\section{B. Metode Pemodelan}

1. Pemodelan Fungsional dengan Use Case Diagram

Use case (Schmuller, 2004, p13) adalah sebuah gambaran dari fungsi sistem yang dipandang dari sudut pandang pemakai (a use

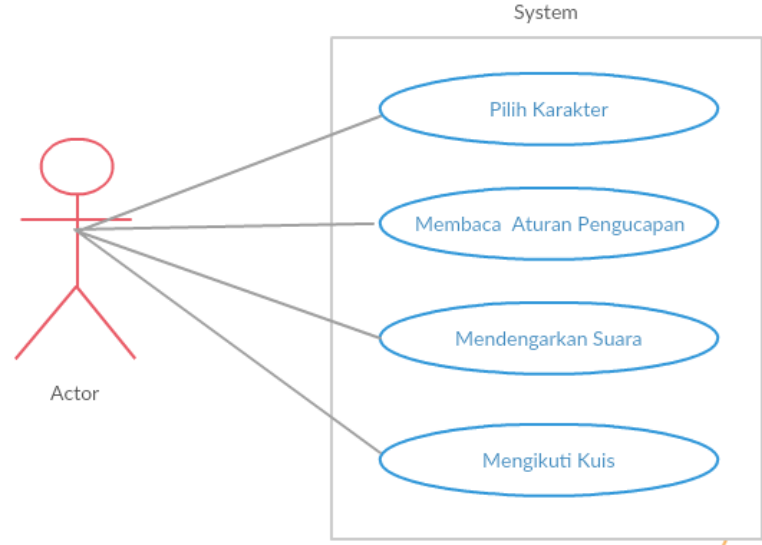

Gambar 3. Use Case Diagram

case is a description of a system's behavior from a user's Stand Point)[6].Pemodelan Fungsional dalam penelitian ini dibuat menggunakan use case diagram. Semua fungsi yang ada dalam aplikasi ini digambarkan melalui use case diagram.Gambar use case diagram aplikasi pembelajran makhraj huruf Al-Qur'an dapat dilihat pada gambar3.

2. Pemodelan Obyek/Struktur menggunakan Class Diagram

Kelas (Schmuller, 2004, p11) adalah sebuah kategori atau pengelompokan dari hal-hal yang mempunyai atribut dan fungsi yang sama ( $a$ class is a category or group of things that have similar attributes and common behaviors)[7].Pemodelan Obyek/Struktur dalam penelitian ini dibuat menggunakan class diagram.Class diagram dibuat untuk menelompokkan fungsi antara sistem dan user. Dalam class diagram yang dibuat, hanya ada 2 kelasyaitu user dan aplikasi. User memiliki fungsi untuk mengakses aplikasi sedangkan sistem menampilkan aplikasi yang dibuat. Berikut merupakan class diagaram untuk aplikasi pembelajaran makhraj huruf AlQur'an dapat dilihat pada gambar 4.

3. Pemodelan Behavior dengan menggunakan Sequence Diagram

Sebuah sequencediagram (Lethbridge danLaganiere, 2005, p286), menunjukkan urutanpertukaran pesan yang dilakukan oleh

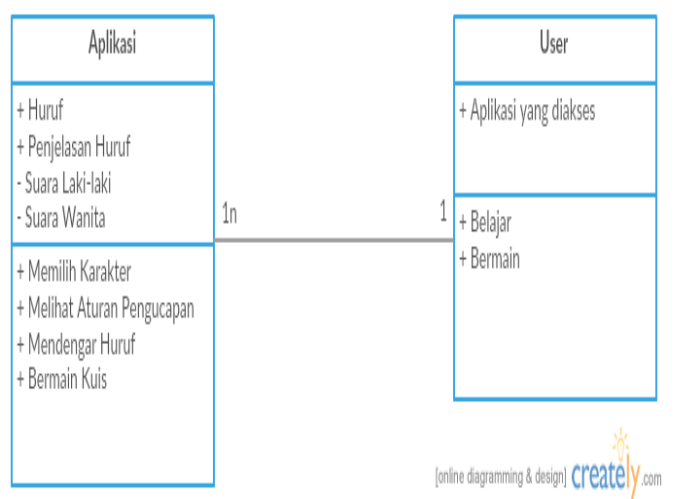

Gambar 4. Class Diagram 
sekumpulan objek atau actor yang mengerjakan pekerjaan tertentu(asequencediagramshowthe sequenceofmessagesexchangedbythesetofobjects( andoptionallyanactor) performingacertain task)[8].Pemodelan Behavior dalam penelitian ini dibuat menggunakan sequence diagram.Sequence diagram menggambarkan proses berjalannya aplikasi yang menggambarkan jalannya/proses berjalannya aplikasi antara userdan sistem.Sequence diagram dari aplikasi pembelajaran makhraj huruf AlQur'an dapat dilihat pada gambar 5.

\section{Bagan Air}

Bagan alir program merupakan bagan yang menjelaskan secara rinci langkah langkah dari proses program. Bagan alir program dibuat dari derivikasi bagan alir sistem. Dalam membuat suatu program, dibutuhkan rancangan prosedur awal dalam proses menjalankan aplikasi bisa dibuat menggunakan bagan alir[9].Pemodelan langkah-langkah dari aplikasi yang akan dibuat menggunakan bagan alir. Dalam membuat suatu program, dibutuhkan rancangan prosedur awal dalam proses menjalankan aplikasi bisa dibuat menggunakan bagan alir. bagan alir berguna untuk menganalisis kecukupan prosedur pengendalian di dalam suatu sistem, seperti pemeriksaan internal dan pemisahan fungsi. Gambar 6 merupakan bagan alir dari aplikasi pembelajaran makhraj huruf Al-Qur'an.

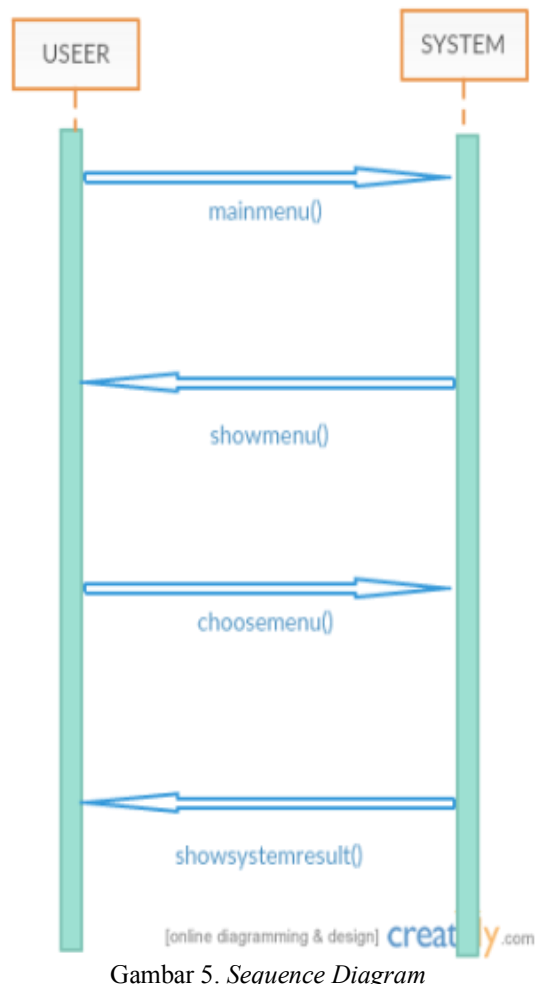

Gambar 5. Sequence Diagram

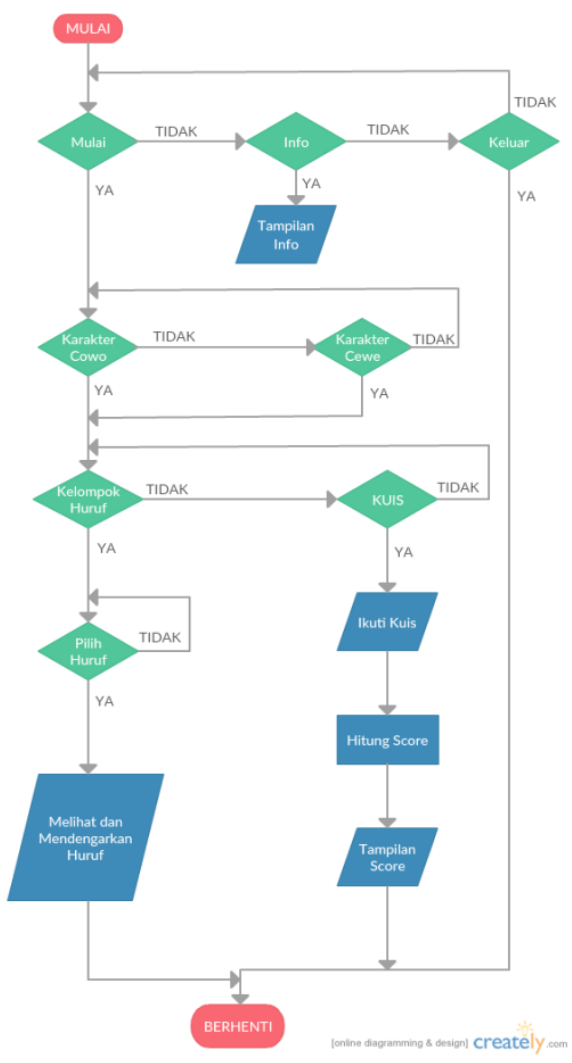

Gambar 6. Diagram Alir

\section{HASIL DAN PEMBAHASAN}

\section{A. Karakter}

Aplikasi ini mempunyai fitur memilih karakter, dalam pemilihan karakter aplikasi menyediakan 2 pilihan karakter. Yaitu laki-laki dan perempuan. Tampilan karakter dalam aplikasi terdapat pada gambar 7.

Gambar 7 merupakan gambar tulang karakter kedua karakter yang telah dibuat. Gambar pertama merupakan tampak depan tulang dan gambar kedua merupakan tampak samping tulang. Tulang yang dibuat adalah tualang kepala, siku, jari, mulut dan lutut.

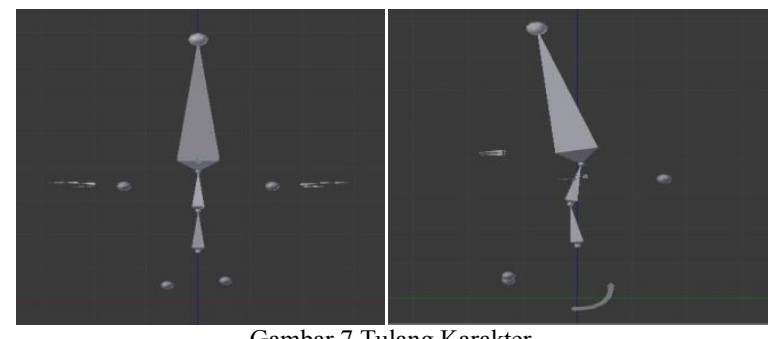

Gambar 7 Tulang Karakter 

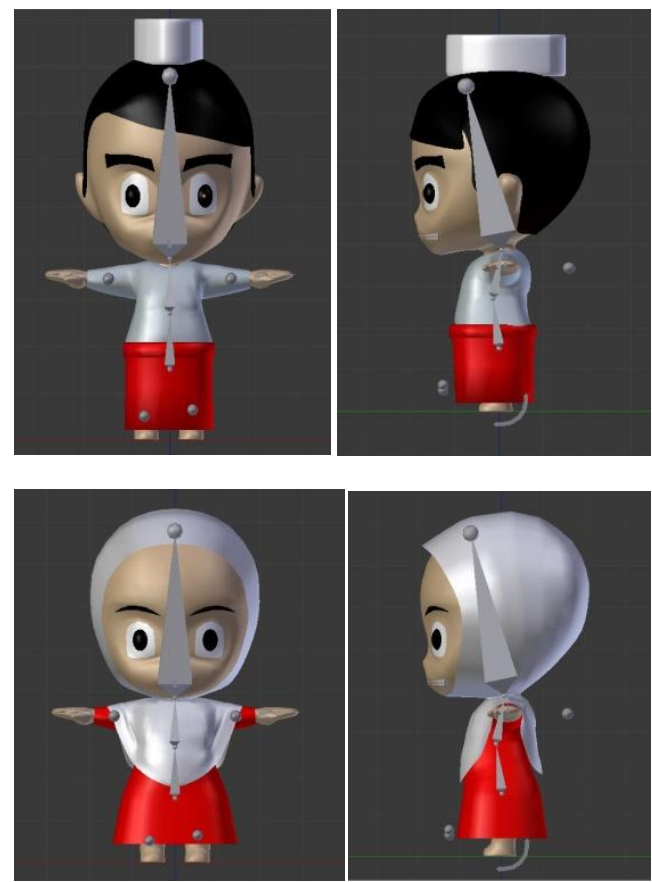

Gambar 8 Karakter yang Dimasukkan Tulang

Gambar 8 merupakan gambar saat karakter dimasukkan tulang.Tulang yang dimasukkan harus sejajar dengan karakter yang telah dibuat.Tulang yang dibuat harus sesuai dengan karakter yang diinginkan agar tidak salah dalam memasukkannya.Dan tulang yang dimasukkan harus benar, agar nanti karakter bisa mengikuti gerakkan sesuai tulang yang dimasukkan.

Gambar 9 adalah gambar karakter laki-laki yang telah dimasukkan tulang didalamnya. Gambar yang pertama adalah gambar tampak depan karakter. Gambar kedua adalah gambar tampak kiri karakter.Gambar ketiga adalah gambar tapak kanan karakter dan gambar terakhir adalah gambar tampak belakang karakter.Karena karakter telah dimsukkan tulang, maka karakter bisa berdiri mengikuti gerakkan tulang.
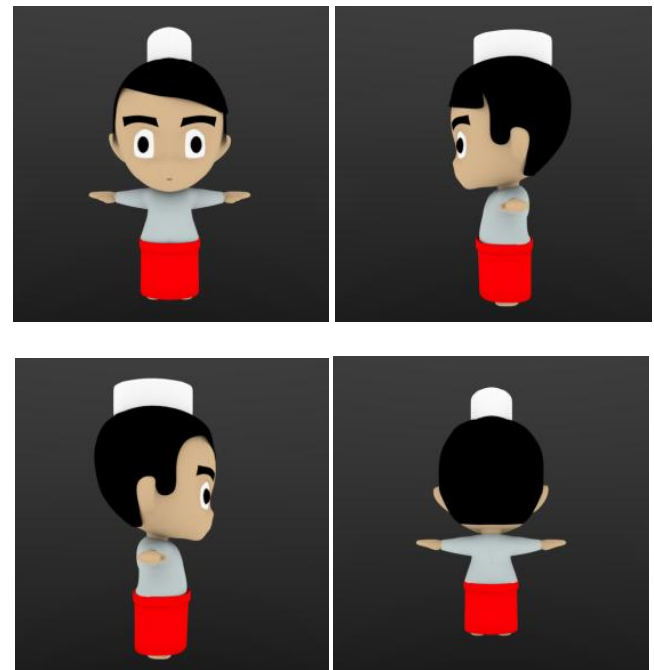

Gambar 9 Karakter Laki-laki yang Telah Dimasukkan Tulang

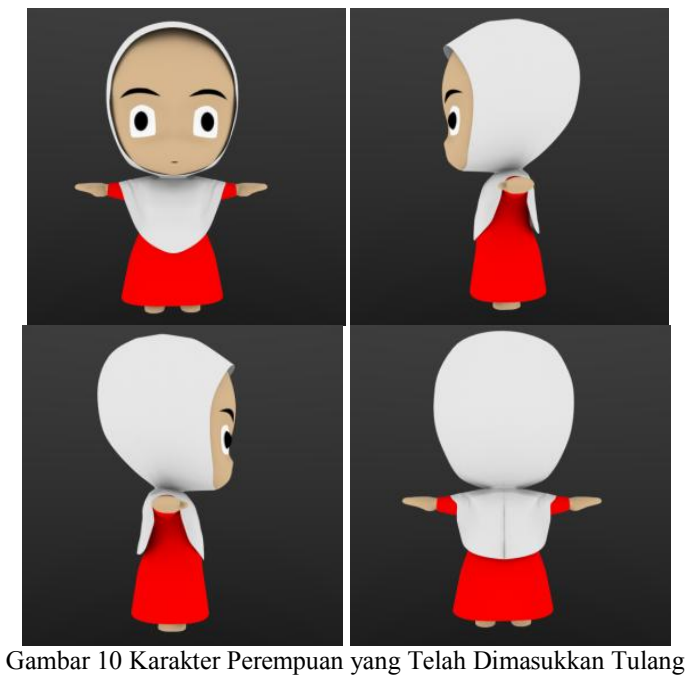

Gambar 10 adalah gambar karakter perempuan yang telah dimasukkan tulang didalamnya. Gambar yang pertama adalah gambar tampak depan karakter. Gambar kedua adalah gambar tampak kiri karakter.Gambar ketiga adalah gambar tapak kanan karakter dan gambar terakhir adalah gambar tampak belakang karakter.Karena karakter telah dimsukkan tulang, maka karakter bisa berdiri mengikuti gerakkan tulang.

\section{B. Interface Aplikasi}

Hasil dari penelitian ini adalah aplikasi pembelajaran makhraj huruf Al-Qur'an yang dikhususkan untuk anakanak. Gambar 11 merupakan gambar tampilan awal aplikasi. Tampilan ini adalah tampilan kedua yang akan muncul saat aplikasi djalankan. Tampilan pertama yang akan muncul adalah tampilan splash screen, dimana tampilan tersebut berisi loading bar dan logo pembuat aplikasi. Pada tampilan awal aplikasi terdapat empat menu utama yaitu menu mulai, menu kuis, menu info dan menu keluar.

Gambar 12 merupakan tampilan pilih karakter dalam aplikasi. Tampilan ini akan muncul apabila user memilih menu mulai pada tampilan awal (gambar 11). Pada tampilan ini aplikasi memberikan pilihan kepada user untuk memilih karakter yang akan digunakannya. Aplikasi menyediakan dua karakter didalamnya karakter tersebut adalah karakter laki-laki dan karakter perempuan.

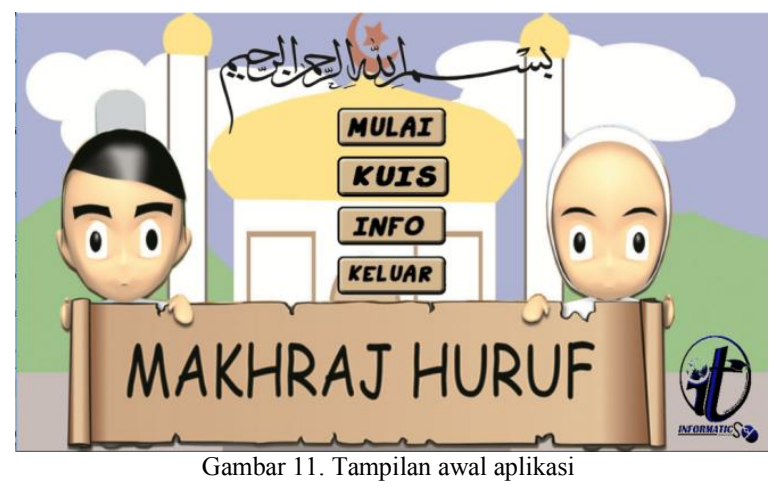




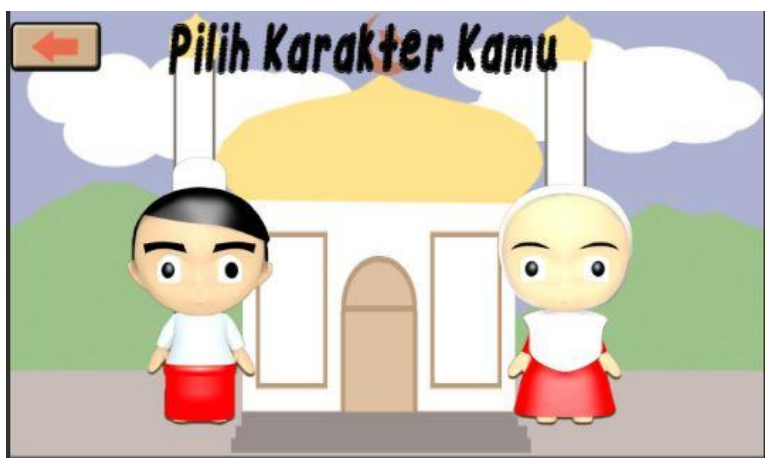

Gambar 12. Tampilan Pilih Karakter

Gambar 13 merupakan gambar tampilan disaat karakter laki -laki yang dipilih memperkenalkan namanya masing-masing. Sedangkan untuk karakter perempuan bisa dilihat pada gambar 14. Karakter akan tampil dengan berputar sambil mengeluarkan suara perkenalan mereka masing-masing. Tampilan ini akan muncul ketika user telah memilih karakter yang akan digunakan pada tampilan sebelumnya yaitu tampilan pilih karakter (gambar 12) yang mempunyai 2 karakter didalamnya yaitu karakter perempuan dan karakter laki-laki.

Gambar 15merupakan tampilan melihat dan mendengarkan huruf untuk karakter laki-laki. Sedangkan untuk karakter perempuan bisa dilihat pada gambar 16 . Tampilan ini akan muncul ketika user telah memilih huruf apa yang ingin dilihat dan didengarkan penjelasannya pada tampilan sebelumnya yaitu tampilan pilih huruf. Apabila user ingin mendengar cara pengucapan huruf tersebut, maka user bisa menekan tombol huruf yang dipilih yang berada diatas penjelasan huruf. Maka karakter yang berada tepat disamping penjelasan huruf akan nmengeluarkan suara mengenai huruf tersebut atau cara pengucapan huruf tersebut.

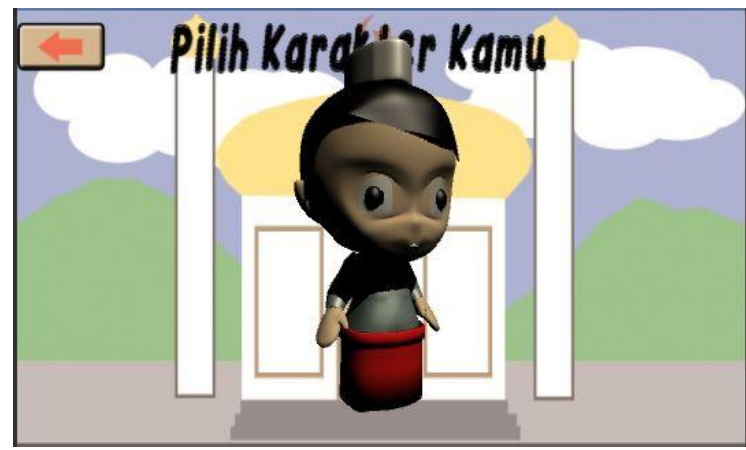

Gambar 13. Perkenalan Karakter Laki-laki

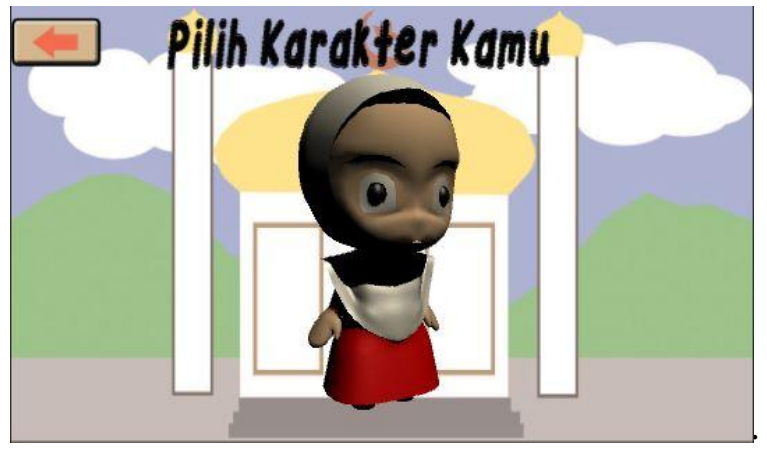

Gambar 14. Perkenalan Karakter Perempuan

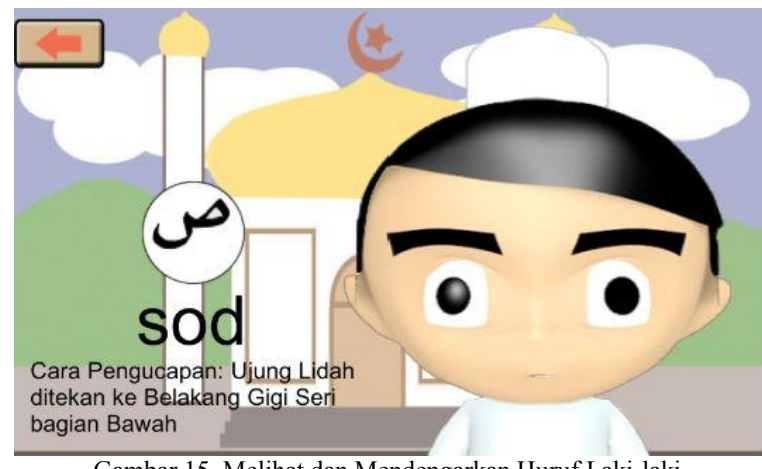

Gambar 15. Melihat dan Mendengarkan Huruf Laki-laki

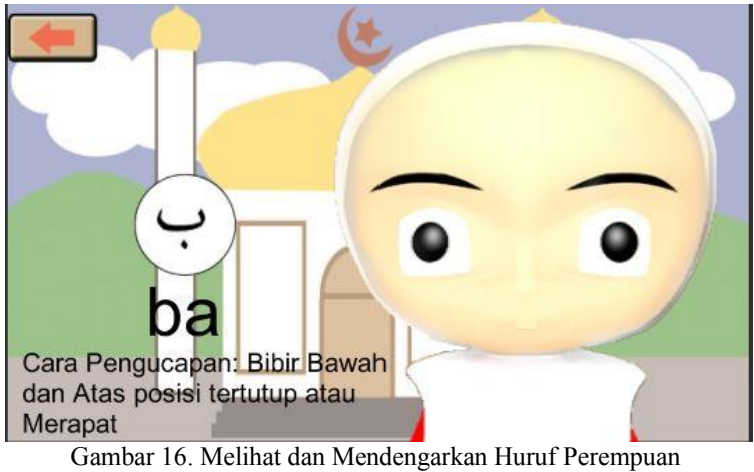

Gambar 17 merupakan gambar tampilan kuis. Aplikasi ini menyediakan 15 pertanyaan dan dua pilihan jawaban. Kuis tidak akan berhenti sebelum user menjawab kelima belas pertanyaan yang telah disediakan.

Gambar 18 merupakan gambar tampilan untuk score kuis. Setelah kuis diselesaikan (gambar 17) maka akan muncul tampilan score, dimana tampilan score menampilkan jawaban yang benar dan jawaban yang salah pada kuis yang telah diikuti user sebelmnya.
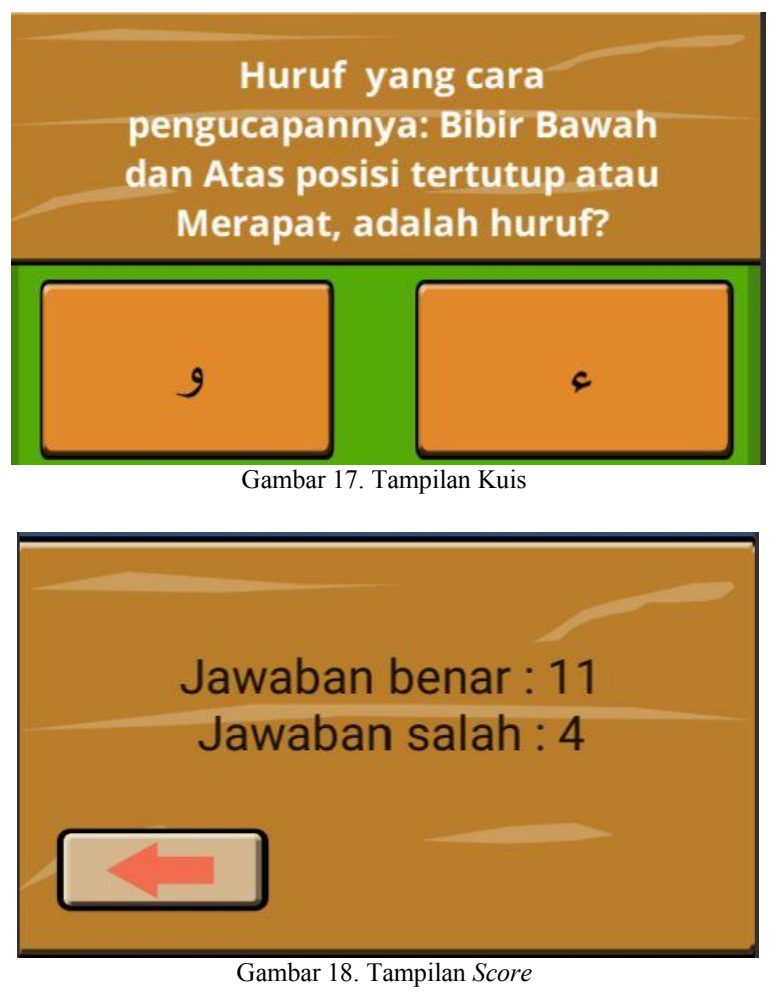


\section{PENUTUP}

\section{A. Kesimpulan}

Dari penelitian yang telah dilakukan telah didapatkan keseimpulan bahwa telah dibuatnya suatu aplikasi pembelajaran makhraj huruf AlQur'an yang sesuai dengan kebutuhan pengguna.Untuk menggunakan aplikasi ini anakanak harus diawasi oleh orang dewasa yang lebih memahami makhraj huruf.Karena makhraj huruf memiliki tingkat kesulitan yang berbeda disetiap hurufnya. Hasil dari aplikasi pembelajaran makhraj huruf Al-Qur'an adalah:

1. Materi tentang tempat keluarnya huruf AlQur'an (makhraj huruf) yang berisikan 29 huruf.

2. Karakter yang disediakan berjumlah 2 karakter yaitu laki-laki dan perempuan.

3. Kuis yang bisa diikuti pengguna sebagai tolak ukur pengguna bisa menguasai materi yang diberikan. Materi dalam kuis berjumlah 15 soal. Dimana soal-soal tersebut merupakan hasil dari materi yang diberikan sebelumnya.

4. Aplikasi yang dihasilkan berplatform android.

B. Saran

1. Aplikasi yang dibuat dapat ditambah audio yang menarik agar bisa lagi lebih memikat anak-anak untuk menggunakanya.

2. Fitur yang terdapat dalam aplikasi bisa ditambah dengan fitur tajwid yang lainnya.

3. Animasi yang didalam aplikasi bisa dimodifikasi agar lebih detail mengikuti dalam penjelasannya.

4. Fitur kuis bisa ditambah lagi pertanyaannya sesuai dengan materi yang ada didalamnya.

5. Tolak ukur dalam aplikasi ini bisa ditambah lagi selain kuis yang sudah dibuat.

\section{DAFTAR REFERENSI}

[1] Suyandra Eko Mukti. Ridoaldi Syafitra. Rusbandi. "Rancang Bangun Aplikasi Bimbingan Akademik Berbasis Web dan Android pada Program Studi Manajemen S1 STIE MDP”. STMIK GI MDP. 2012

[2] United Islamic Cultural Centre of Indonesia. Tajwid Qarabasy. E-book. Rawamangun-Jakarta Timur. 2005

[3] Gelli Studio. Mengenal Unity. http://gellistudio.com/mengenal-unity3d/ Agustus 2015]

[4] Ali Zaki. Edy Winarno ST, M.Eng. SmitDev Community. Animasi Karakter dengan Blender dan Unity. PT Elex Media Komputindo. Jakarta. 2016

[5] Roby Harris, 2012, " Fungsi game edukasi ", (Online), (http://elib.unikom.ac.id/files /disk1/577/jbptunikompp-gdl-robbyharis-28847-9unikom_r-i.pdfInfinite Editing. Pengertian Ringkas Mengenai Adobe Photoshop. http://www.infiniteediting.com/2014/10/. September 2016]

[6] Fowler, Martin. Sams Teach Yourself UML in 24
Hours Third Edition, Schmuller, p13. 2005

[7] Fowler, Martin Sams Teach Yourself UML in 24

Hours Third Edition, Schmuller,p11. 2005

[8] Fowler, Martin Object Oriented Software Engineering: Practical Software Development Using UML and Java. Mcgraw Hill-Education,Timothy Lethbridge dan Robert Laganiere, p287. 2005

[9] Dwinky Andhika. Pengertian Flowchart.https://www.it-jurnal.com/pengertianflowchart/ . [2 September 2016]

\section{SEKILAS TENTANG PENULIS}

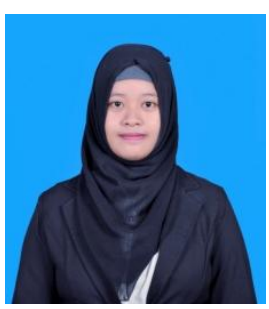

Gitadea Laksono, lahir di Manado, Sulawesi Utara pada tanggal 30 Agustus 1994. Penulis menempuh pendidikan di Sekolah Dasar Negri 57 kota Manado. Selanjutnya penulis meneruskan pendidikan di Sekolah Menengah Pertama Negri 1 Manado. Dan penulis melanjutkan pendidikan di Madrasah Aliyah Pondok Pesantren Assalam Manado dan mengambil jurusan IPA. Penulis merupakan seorang mahasiswa Program Studi Informatika, Jurusan Teknik Elektro, Fakultas Teknik, Universitas Sam Ratulangi pada tahun 2012 - 2017. Selama masa kuliah, penulistelah menjalani kerja praktek di Pusat Teknologi dan Informasi Universitas Sam Ratulangi Manado, mengikuti kegiatan KuliahKerja Terpadu di Desa Tontalete Rokrok, Kabupaten Minahasa Utara. 
